\title{
An Analysis of Price Behavior of Major Poultry Products in Sri Lanka
}

\author{
A. R. Wickramarachchi ${ }^{1}$, H. M. L. K. Herath ${ }^{1}$, U. K. Jayasinghe-Mudalige ${ }^{1^{*}}$, \\ J. C. Edirisinghe ${ }^{1}$, J. M. M. Udugama ${ }^{1}$, L. D. M. N. Lokuge ${ }^{1}$ and W. Wijesuriya ${ }^{2}$
}

Received: $14^{\text {th }}$ June 2016 / Accepted: $9^{\text {th }}$ January 2017

\begin{abstract}
Taking its overall importance to the economy, as a whole, including food and nutrition security and better performance of the food supply chain from producer to the consumer, the successive governments tend to take a variety of initiatives to upkeep the sustainability of agri-food supply system, but the scarcity of valid and reliable information on the behavior of prices makes it challenging for policymakers to have timely economic decisions. This study attempts to examine the behavior of prices of major poultry products, including chicken (broiler and curry) and eggs (brown and white) on the justification that which have become regular food items in Sri Lankan menus overtime and the total chicken and egg production in Sri Lanka has increased markedly by about 45.3 and 64.5 percent, respectively, during the period of 2003 to 2012. The time-series data were taken up with advanced econometrics models on price analysis, including the ARIMA and SARIMA models which provide efficient forecasts of weekly real prices of different poultry products. It founds that the increasing trend apparent in nominal prices was due to rising inflation of the economy, and the real prices of these products stagnated overtime.
\end{abstract}

Keywords: Forecasting, Poultry industry in Sri Lanka, Price analysis, SARIMA and ARIMA models

\section{INTRODUCTION}

The high and fluctuating food prices, especially for those 'essential' food items such as rice, wheat flour, sugar, milk, red meat and poultry products, can have a greater impact on food and nutrition security, both at the household and national level. For a small country like Sri Lanka characterized by apparent failures in income distribution where a relatively large portion of households fall into the profile of low income, insufficient domestic food production that does not guarantee a balanced diet, and inadequate allocation of land for agriculture and livestock due to high population density (i.e. nearly 23 million population lives in about 65,000 square $\mathrm{km}$ of land), it can pose negative impacts on the level of employment, and proper functioning of agri-food supply chains at each level from production to consumption.
All these factors, directly or indirectly, have unhealthy consequences on the economy which can create numerous issues at the macroeconomic level, including dampening investments due to diminished domestic savings. At present, the country, for the most part, depend on importation of major food items and other raw materials required for its production and manufacturing activities. However, the potential impact of changing food prices on socio-economic aspects of a country, including food security at the household level, may depend on the state of politics, geography, and particularly on the nature of commodity in concern. Customarily, a country should stabilize the prices of essential commodities so that it can run its commodity markets with minimal failure. Price instability is a substantial issue for those 
countries with unstable food supply systems, and as a result, food security largely depends on food importation. Although it is difficult to measure the exact costs of food price instability from a given country perspective, the total macroeconomic costs may likely to be small for those countries with diversified production and food consumption only.

Those studies that focus on price analysis are somewhat diverse from the point of view of problem they have addressed in terms of the country, product and market structures in concern, but, in general, have highlighted that stabilization of food prices at a desired level can contribute to economic growth and increased general welfare of consumers. Timmer (2013), for example, focusing on Indonesian economy, showed that stabilization of rice prices enhances the overall growth of the economy nearly by one percent. In a similar study, which examined the gain of price stability on the welfare cost of price instability in Indonesia, Myers (2006) found that it can be around 5 to 11 percent of the economy-wide income per year. Nevertheless, updated scientific information and publications on similar issues in the context of Sri Lanka is scarce other than mass scale mass media and web postings of various issues and their repercussions on different stakeholders along the food supply chain. What is available in economic literature on price analysis, then again, has limited to the rice markets, given its high importance to the economy.

Jayasinghe-Mudalige (2006), for example, examines the impact of price originated in the Central Rice Market (i.e. Colombo) on the price formation in a set of geographically dispersed Regional Rice Market in Sri Lanka using the monthly retail prices. The outcome of this analysis suggests that prices in these markets, irrespective of the whether they are surplus or deficit markets, were highly integrated both in the short-run and long-run perspectives. Sandika (2009) attempt to develop price forecasting models for rice varieties using annual nominal market price and found that Compound Growth Model was the most appropriate to analyze the price behavior of Samba and Nadu rice, while quadratic model was suitable for Kakulu rice. In another study, De Silva et al. (2006) investigate whether the tuna fish markets in Sri Lanka were integrated to bring efficiency in the marketing system based on time series monthly data in selected wholesale and retail fish markets and revealed that all the selected tuna fish markets in Sri Lanka were integrated and showed short run stability.

In the absence of valid, reliable and timely information with regard to price behavior, it is vital to assess so for the most popular and essential commodities such as poultry products (i.e. meat and egg), since such knowledge would help vastly to identify the market behavior of those products, investigate their future market trends, and more specifically to make forecasts and useful simulations for better decision making. Next, a brief description about the current status of poultry industry in Sri Lanka is provided to provide the rational for this analysis.

Over the past three decades, Sri Lankan poultry industry has developed into a commercial industry from being a backyard-type industry. During this process, poultry products became an essential food item in Sri Lankan menus. The total chicken and egg production has increased from 9.7 to 14.1 million kilograms (i.e. $45.3 \%$ ) and 73.7 to 121.4 million (64.5\%), respectively, from 2003 to 2012 (Department of Census and Statistics, Sri Lanka, 2012). On the rationale that production and consumption of poultry products play a significant role to improve the socio-economics of Sri Lankans in terms of food and nutrition security, employment, marketing and trade etc., government, at various levels from local, provincial to state, has taken several initiatives, including the government's declaration of chicken meat as an essential food item as early as 2007 (Wijewantha et al., 2010). 
The demand for both chicken meat and eggs are customarily high during the festival seasons in Sri Lanka, i.e. April (Sinhalese and Tamil New Year period) and December (Christmas and year-end vacations), and market is subject to fluctuations of price and quantities. Such fluctuations may be a result of both internal and external factors, especially implications of trade policies, governmentregulations targeting prices and supply control. It was estimated that poultry feed account for almost 70 percent of the cost of production of chicken meat and eggs; thus, the market price of poultry products could largely be decided upon by existing and fluctuations to prices of feed, and this is aggravated by the fact that the industry is highly depending on the importation of raw materials needed to prepare poultry feed, mainly maize and soya bean meal. In fact, prices of these items were showing, on an average an upward trend in the recent years (Wijewantha et al., 2010).

Thepoultrysectorhas showntremendousgrowth, predominantly in the broiler sector, mainly due to private sector engagement throughout the product supply chain from production through value addition to consumption. At present, two local grand-parent farms produce nearly 70 percent of country's requirements of parent birds. Although a relatively large number of local feed manufacturers scattered over the country are involved with poultry feed production at various capacities, and contribution of two multinational firms in this respect is much prominent. Yet, around 85 percent of raw materials to manufacture poultry feed are currently being imported. Further, chicken meat and eggs are available throughout the country from small retail grocery shops in remote rural areas to large-scale supermarket chains in the main cities as well as in specialized shops set for the purpose. With all these facilitation to up-scale the industry from various stakeholders representing both private and public sector through a variety of promotional programs and regulatory mechanisms, the per capita availability of chicken meat and eggs at present is reported as $4.8 \mathrm{~kg}$ and 57 , respectively (Ministry of Social Services, Welfare and Livestock Development, 2012).

Facts presented above suggest that the poultry producers, especially those operating at smallscale, have become more vulnerable to market pressures due to variable feed prices, which, as in many other industries, may be 'favorable' for those firms operating at large-scale as they can 'bear with the situation' relatively to their counterpart. In fact, gradually, this situation could lead into creation of a monopoly in the market for leading poultry products such as broiler meat and raw eggs. Moreover, consumer prices of chicken meat and eggs are rated as high amongst most of the countries in the Asian region.

In a situation where, both these products become essential items in the consumer food basket with limited substitutes and large number of people are involved in various capacities in the food supply chain, it is of paramount importance for both private (firms, marketers) and public (government) sector stakeholders to get to know the depth and reasons for these fluctuations for better planning, decision making, and forecasting.

In light of this, this study was aimed to carry out a comprehensive price analysis on major poultry products in Sri Lanka which have now become a regular food item of Sri Lankan consumers. The paper will next present the theoretical framework used for the analysis followed by the outcome of price analysis, major conclusions and implications of which to the policy.

\section{METHODOLOGY}

\section{Theoretical Framework and Data}

The weekly time series data on Colombo Average Retail Prices from year 2000 to 2013 for several poultry products, including Broiler, Curry chicken, Brown eggs, and White eggs 
were collected from the database administered by the Hector Kobbakaduwa Agrarian Research and Training Institute (HARTI) of Sri Lanka. These price data were available as "nominal prices'; thus, to facilitate a systematic price analysis, it was a requisite that convert these nominal prices into the 'real prices'.

Customarily, the Colombo Consumer Price Index (CCPI) constructed by the Department of Census and Statistics of Sri Lanka is used as the official Consumer Price Index for economic analysis. By definition the CCPI is an inflationary indicator that measures the change in the cost of a fixed basket of products and services, including 334 items categorized in 10 groups that include health, transport, food and nonalcoholic beverages, communication, clothing and footwear, education, housing, water, electricity, gas and other fuels', and the value of which is published on monthly basis. Department of Census and Statistics (DCS) constructed a more comprehensive CPI called the Colombo Consumers' Price Index (Base 2002=100) in November 2007 addressing many of the deficiencies exist earlier, and which was accepted as the official measure of inflation in Sri Lanka in November 2007, replacing the outdated Colombo Consumer Price Index CCPI (Base: 1952=100). To be consistent with similar analyses, this analysis was also followed the same procedure, and is summarized below.

Let Nominal price at time $t$ is $p n_{t}$ and Real price at time $t$ is $p r_{t}$, where $t=1,2 \ldots T$. Then, $p r_{t}$ can be defined as depicted in equation 1 :

$p r_{t}=p n_{t} \times I C C P I_{t}$

Where,

$I C C P I_{t}=\frac{C C P I_{T}}{C C P I_{t}} \cdot I C C P I_{t} \quad$ serves as an adjustment tactor which delivers the proportionate increase in price between $t$ and $T$. Hence, it can be interpreted as the ratio between the CCPI at time $T$ and the CCPI at time $t$, which is the most recent value of CCPI in the series. The CCPI values belong to two different base periods were brought into a one base period using a conversion ratio, which was calculated using a set of CCPI values calculated for a same period using both base periods (Sahr, 2013).

In time series forecasting, Auto-Regressive Integrated Moving Average (ARIMA) and Seasonal Auto-Regressive Integrated Moving Average (SARIMA) models have become more popular and, they are widely used due to their statistical properties as well as the Box-Jenkins methodology used in the model structure (Zhang, 2003; Chen and Wang, 2007). ARIMA and SARIMA models are extensions of AutoRegressive Moving Average (ARMA) class, and they facilitate more realistic dynamics. Many economic time series are often nonstationary in Mean, and in consequently, the non-stationary source of variation should be removed prior to modelling. This can be completed by differencing the series, where ARIMA removes non-stationarity in the Mean and SARIMA does the seasonality in the series (Gerolimetto, 2010).

Consequently, the ARIMA and SARIMA approaches were employed to develop the theoretical model by utilizing set of real prices for time series price data. Let the time series random variable is $\left\{Y_{t}: t \in T\right\}$; then, an ARIMA process and a SARIMA process can be depicted as in the forms shown in equation 2 and 3 , respectively (Shumway and Stoffer, 2006).

$$
\begin{aligned}
& \phi(B) \nabla^{d} y_{t}=\alpha+\theta(B) \varepsilon_{t} \\
& \Phi_{P}\left(B^{s}\right) \phi(B) \nabla_{s}^{D} \nabla^{d} y_{t}=\alpha+\Theta_{Q}\left(B^{s}\right) \theta(B) \varepsilon_{t}
\end{aligned}
$$

where, $\varepsilon_{t}$ denotes a Gaussian white noise process. Gaussian noise is a statistical noise in which its Probability Density Function (PDF) lies with that of the normal distribution, which is also known as the Gaussian distribution (Barbu, 2013). White Gaussian noise is a special case where the values at any pair of times are identically distributed and statistically independent (and hence, uncorrelated). The terms $\phi(B)$ and $\theta(B)$ represent the Ordinary 
Autoregressive and Moving Average operators of orders $p$ and $q$. Further, the terms $\Phi_{P}\left(B^{S}\right)$ and $\Theta_{Q}\left(B^{S}\right)$, respectively, stand for 'Seasonal Autoregressive' and 'Moving Average' operators of order $P$ and $Q$. The Ordinary Differencing Component can, therefore, be written as:

$$
\nabla^{d}=(1-B)^{d}
$$

, whereas the Seasonal Differencing Component can be presented in the form of:.

$$
\nabla_{s}^{D}=\left(1-B^{s}\right)^{D}
$$

Prior to fitting the orders $\mathrm{p}, \mathrm{q}$, the terms $\mathrm{P}$ and $\mathrm{Q}$ were identified using respective Autocorrelation Functions (ACF) and Partial Autocorrelation Functions (PACF). The 'stationarity' and the 'order of ordinary' and 'seasonal differencing' were, in turn, recognized by way of Augmented Dickey Fuller (ADF) test (Said and Dickey, 1984); Kwiatkowski-Phillips-Schmidt-Shin (KPSS) test (Kwiatkowski et.al, 1992), and the respective ACFs and PACFs. In the process of model fitting, Maximum Likelihood Estimates (MLEs) of the parameters were computed using ' $\mathrm{R}$ package', while the 'TSA' and 'Goodnessof-fit' was examined by using AIC, AICc and BIC (Shumway and Stoffer, 2006). Further, the 'forecasting efficiency' was checked using the Mean Absolute Percentage Error (MAPE), where the training dataset was taken for the period of year 2000 to 2011 and validation set was considered for the period of 2012 to 2013. The Forecasting efficiency and forecasts for 2014 were obtained using the $\mathrm{R}$ package "Forecast".

\section{RESULTS AND DISCUSSION}

\section{Descriptive Statistics and Time Series Plots of Prices}

Table 01 reports the descriptive statistics pertaining to prices of Broiler chicken, Curry chicken, Brown eggs, and White eggs. The Real prices of Broiler chicken and Curry chicken, respectively, were ranged from Rs. 341.76 to Rs. 685.64 and Rs. 341.76 to Rs. 674.51 within the period of concern for this analysis. Further, it shows that the average real price of Broiler chicken and Curry chicken were Rs. 481.25 and Rs. 464.55, respectively, and the prices were dispersed within a relatively small range of 53.39 and 50.96. The average real price of Brown egg and White egg, respectively, during this period was Rs. 13.96 and Rs. 13.26. The minimum poultry prices were recorded in 2009, which was caused by lack of consumer demand for poultry products resulting from health concerns of consumers related to global spread of 'bird-flu disease'.

Table 01: Descriptive statistics of real prices.

\begin{tabular}{lcccc}
\hline & Broiler Chicken & Curry Chicken & Brown Egg & White Egg \\
\hline Mean & 481.25 & 464.55 & 13.96 & 13.26 \\
Standard Deviation & 53.39 & 50.96 & 2.09 & 2.11 \\
Maximum & 685.64 & 674.51 & 20.91 & 20.26 \\
& $(2005)$ & $(2005)$ & $(2010)$ & $(2010)$ \\
Minimum & 341.76 & 341.76 & 8.99 & 8.21 \\
& $(2009)$ & $(2009)$ & $(2012)$ & $(2004)$ \\
Kurtosis & 0.64 & 0.77 & 0.33 & 0.33 \\
Skewness & 0.27 & 0.41 & 0.45 & 0.48 \\
\hline
\end{tabular}


Figure 01 to 4 illustrate the time series plots of nominal and real prices for: (a) Broiler chicken; (b) Curry chicken; (c) White egg, and (d) Brown egg, respectively.

The nominal prices, in general, show an increment in values with time over this period. However, this behavior is not so prominent with real prices. This tells us that the increment apparent in nominal prices of the poultry products in concern is a result of rate of inflation during this period, which was, according to the Annual Reports of Central Bank of Sri Lanka, relatively high as compared to the present values. The Average Annual Rate of Inflation in Sri Lanka, for example, $21.52 \%$ in $1990 ; 15.88$ in $1996 ; 14.10 \%$ in $2001 ; 9.98 \%$ in 2006 , and $7.53 \%$ in 2012 . The forecast value, according to the International Monetary Fund, is $4.7 \%$.

\section{Estimates from Price Analysis}

Table 02 presents the results from ADF and KPSS tests for Stationarity of real price series of different poultry products. Although the outcome of ADF test indicates that all the real price series are 'stationary', the outcome of KPSS test, supported by the respective ACFs and PACFs, indicates that they are non-stationary. In light

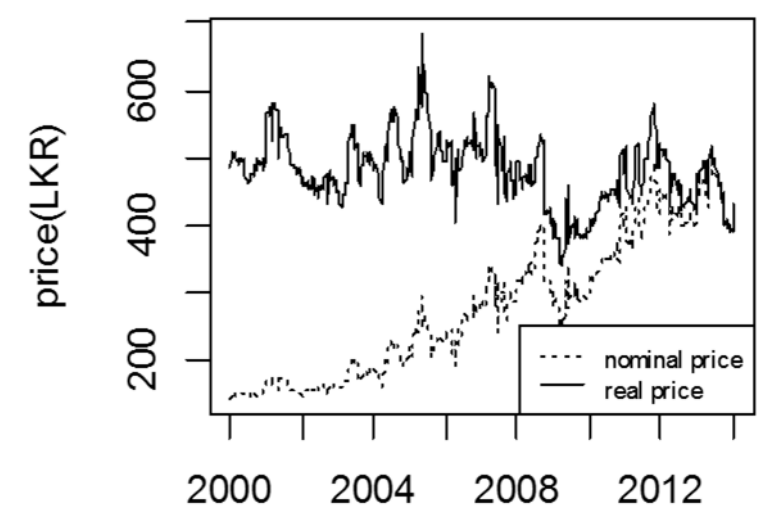

Time

Figure 01: Time series plots of nominal vs real value for Broiler chicken prices of this, we may conclude that all series were 'non-stationary'. Further, the ADF and KPSS tests as well as the ACFs and PACFs applied on respective first-order-differenced series reveal that first-order-differencing is sufficient to imply that all the series are 'stationary'.

The ACF and PACF of first-order-differenced real prices indicate that ARIMA models would exist on real prices of chicken, while there could be a SARIMA model on real prices of eggs. However, the respective ACFs and PACFs verify the fact that real prices of eggs were "seasonally stationary". As a result, the Seasonal Order (Q) of the expected SARIMA model was recognized as "zero". At the time of model fitting and selection, based on the least AICc, the ARIMA $(3,1,1)$ and ARIMA $(0,1,2)$ models, respectively, were identified as the best-fitted models for real price of Broiler chicken and Curry chicken. Similarly, the bestfitted model for Brown egg and White egg was SARIMA $(2,1,2)(0,0,2)$.

Table 03 reports the AICc, estimated parameters with their Standard Errors of the best-fitted models for different poultry products. It shows that estimates of almost all of the models were statistically significant at 5\% level.

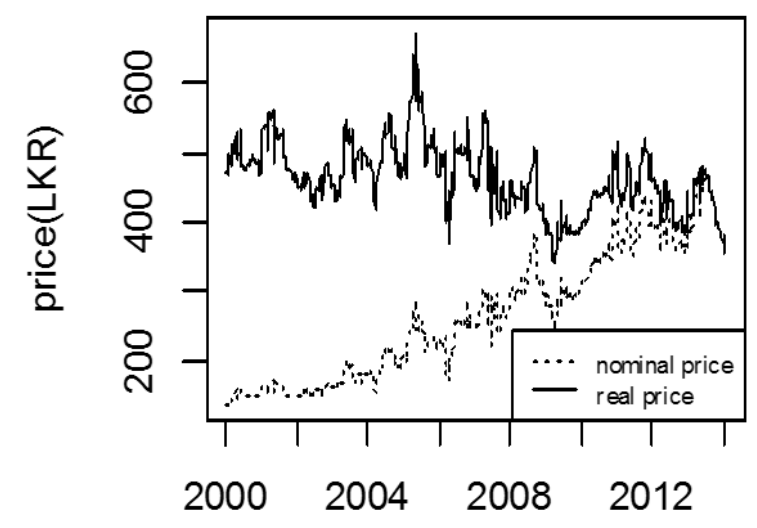

Time

Figure 02: Time series plots of nominal vs real value for Curry chicken prices 


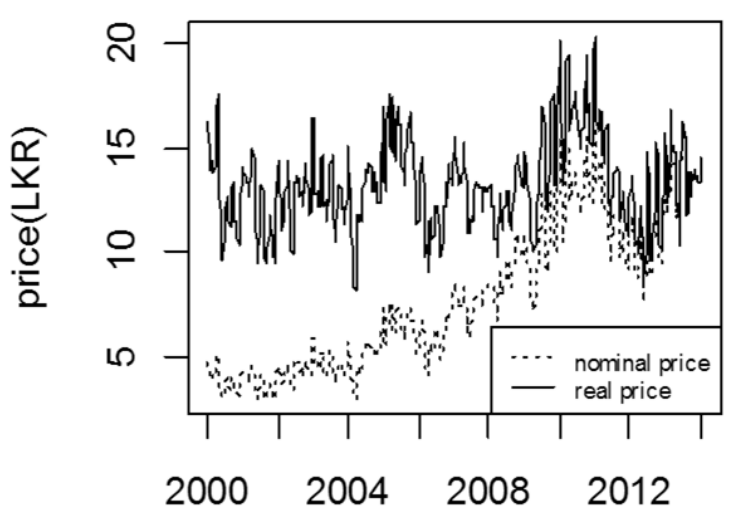

Time

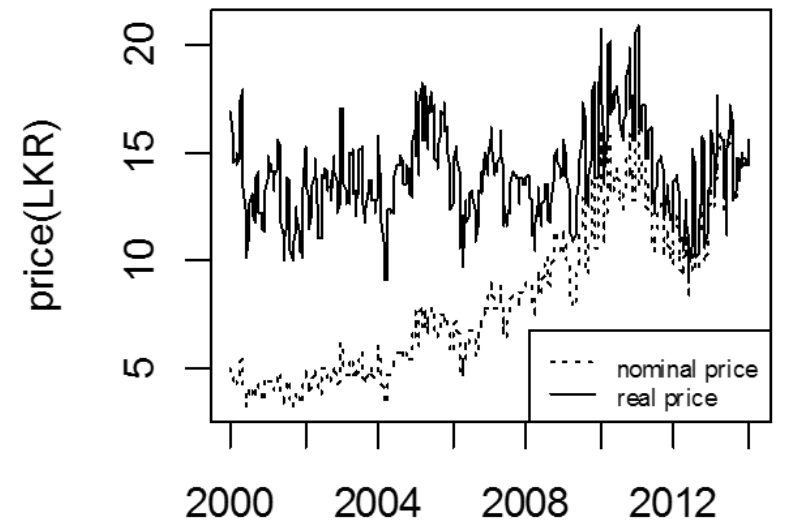

Time

Figure 03: Time series plots of nominal vs real Figure 04: Time series plots of nominal vs real value for White egg prices value for Brown egg prices

Table 02: Estimates of ADF and KPSS tests to evaluate stationarity of real price series.

\begin{tabular}{lccc}
\hline \multirow{2}{*}{ Commodity } & ADF Test & \multicolumn{2}{c}{ KPSS Test } \\
\cline { 3 - 4 } & & KPSS Level & KPSS Trend \\
\hline Broiler Chicken & $-4.006^{* *}$ & $1.8638^{* *}$ & $0.3883^{* *}$ \\
Curry Chicken & $-4.571^{* *}$ & $3.6522^{* *}$ & $0.3407^{* *}$ \\
Brown Egg & $-3.6329^{* *}$ & $0.9101^{* *}$ & $0.1933^{* *}$ \\
White Egg & $-3.6353^{* *}$ & $0.8702^{* *}$ & $0.2038^{* *}$ \\
\hline Wte: $\leq 0.05^{* *} \leq 0.01^{* * *} \leq 0.001$, For ADF Test Ho: data is non stationary, For KPSS Test Ho: data is stationary
\end{tabular}

Table 03: Estimates of the models

\begin{tabular}{lcccccccc}
\hline \multicolumn{1}{c}{ Product } & \multirow{2}{*}{ AICc } & ar1 & ar2 & ar3 & ma1 & ma2 & sma1 & sma2 \\
\hline \multirow{2}{*}{ Broiler } & \multirow{2}{*}{6290.32} & -0.798 & -0.2447 & -0.1695 & 0.6056 & & & \\
& & $(0.135)$ & $(0.0513)$ & $(0.0365)$ & $(0.1336)$ & & & \\
\multirow{2}{*}{ Curry } & \multirow{2}{*}{6278.86} & & & & -0.2011 & -0.0911 & & \\
& & & & & $(0.0365)$ & $(0.0350)$ & & \\
\multirow{2}{*}{ Brown Egg } & \multirow{2}{*}{1524.07} & 1.5758 & -0.7959 & & -1.3551 & 0.4806 & 0.1136 & 0.0665 \\
& & $(0.0423)$ & $(0.0418)$ & & $(0.0604)$ & $(0.0617)$ & $(0.0382)$ & $(0.0384)$ \\
\multirow{2}{*}{ White Egg } & \multirow{2}{*}{1521.32} & 1.5694 & -0.7906 & & -1.3460 & 0.4696 & 0.1107 & 0.0656 \\
& & $(0.0427)$ & $(0.0419)$ & & $(0.0608)$ & $(0.0616)$ & $(0.0382)$ & $(0.0393)$ \\
\hline
\end{tabular}

Note: Values within parenthesis are standard errors of the coefficients

The Residual Analysis on the models presented in Table 03 assured that there were no any violations of the underlying assumptions. In consequently, these models can be accepted as the final models fitted for real prices of the respective products. The Forecasting Efficiency based on MAPE values of the models for these products, i.e. real prices of Broiler and Curry chicken and Brown and White eggs, respectively, were $7.46,8.19,8.25$ and 7.33 percent. This implies that the final models selected through the analysis are "correctly specified" and are 
"rigorous" for the purpose of forecasting. The price forecasts of different poultry products, which use the models specified in Table 03, are given in Table 04.

It can be noticed that most of the forecasts of real prices of poultry products considered in this analysis were close to their actual figures. Moreover, all the actual prices fell within the 95\% Confidence Intervals of the forecasts, which further confirmed the reliability of the fitted model for forecasting. "Seasonal nature" of price of egg was found as the SARIMA models was applied to the real prices of White and Brown eggs. Figure 05 and 06 illustrate the seasonal indices estimated for these products, in turn.

It highlights that real prices of both Brown and White egg fluctuates in more or less similar pattern, i.e. they tend to go up and down in few weeks intervals, i.e. from 4 to 6 weeks, on an average. This indicates a substantial increase in real price of an egg during latter part of the year, especially in December; however, it was comparatively low in April, i.e. during the Sinhala and Tamil New Year season.

Table 4: $\quad$ Real price forecasts of different poultry products for first five weeks in 2014

\begin{tabular}{|c|c|c|c|c|c|}
\hline \multirow{2}{*}{ Commodity } & & \multirow{2}{*}{ Point Forecasts } & \multicolumn{2}{|c|}{ Confident Level (95\%) } & \multirow{2}{*}{ Actual Value } \\
\hline & & & Low & High & \\
\hline \multirow{5}{*}{ 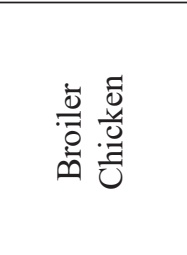 } & $W 1$ & 425.24 & 390.24 & 460.25 & 419.62 \\
\hline & $W 2$ & 425.79 & 380.80 & 470.78 & 417.10 \\
\hline & $W 3$ & 426.13 & 374.62 & 477.64 & 448.51 \\
\hline & $W 4$ & 426.26 & 369.71 & 482.81 & 460.97 \\
\hline & $W 5$ & 425.98 & 363.47 & 488.49 & 484.26 \\
\hline \multirow{5}{*}{ 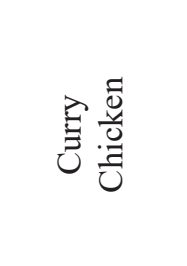 } & $W 1$ & 380.78 & 345.95 & 415.60 & 377.28 \\
\hline & $W 2$ & 380.07 & 335.49 & 424.65 & 377.10 \\
\hline & $W 3$ & 380.07 & 329.13 & 431.01 & 395.64 \\
\hline & $W 4$ & 380.07 & 323.48 & 436.66 & 416.86 \\
\hline & $W 5$ & 380.07 & 318.34 & 441.80 & 447.00 \\
\hline \multirow{5}{*}{ 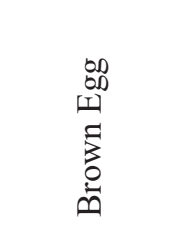 } & $W 1$ & 15.24 & 13.91 & 16.57 & 14.60 \\
\hline & $W 2$ & 15.13 & 13.03 & 17.24 & 14.63 \\
\hline & $W 3$ & 14.94 & 12.26 & 17.62 & 14.61 \\
\hline & $W 4$ & 14.97 & 11.90 & 18.04 & 14.34 \\
\hline & $W 5$ & 15.09 & 11.80 & 18.38 & 14.35 \\
\hline \multirow{5}{*}{ 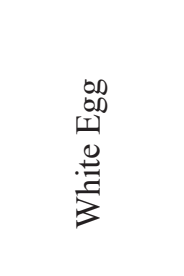 } & $W 1$ & 14.26 & 12.93 & 15.60 & 13.65 \\
\hline & $W 2$ & 14.20 & 12.10 & 16.31 & 13.68 \\
\hline & $W 3$ & 13.96 & 11.27 & 16.65 & 13.64 \\
\hline & $W 4$ & 13.99 & 10.91 & 17.06 & 13.33 \\
\hline & $W 5$ & 14.11 & 10.80 & 17.42 & 13.35 \\
\hline
\end{tabular}




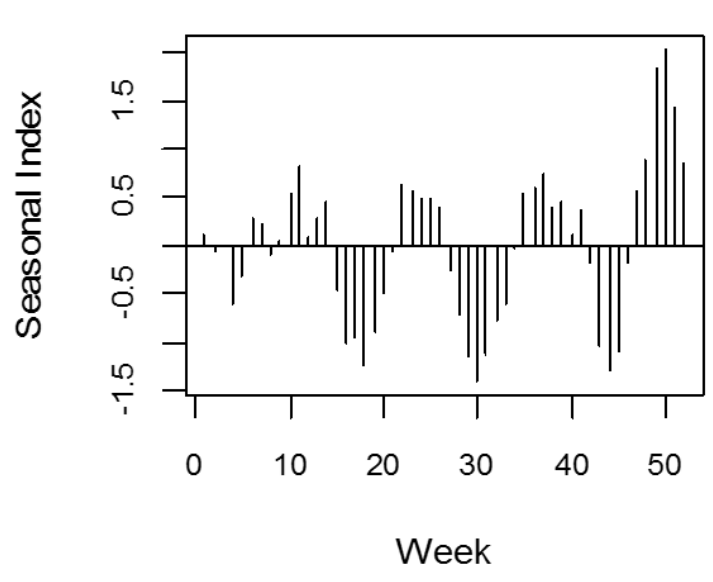

Figure 05: Seasonal index of real prices - Brown egg

\section{CONCLUSIONS}

The outcome of the analysis reveals that, primarily, the increasing trend observed in market prices of poultry products was due to the inflation, which, nevertheless, did have such a negative impact on price not only on poultry products but certain other essential food items during this period (e.g. fish) (see, Perera et al., 2016). Repeatedly, fluctuating exchange rates along with the inflation did have notable negative effects on costs associated with importation of raw materials, including animal feed, drugs and equipment required for poultry production that can have disproportionate shifts in input demand and supply curves. Other than this inflationary effect, it can be seen from this analysis that real prices of eggs did not rise unpromisingly due to other economic reasons that are internal to the industry such as factor mobility (e.g. shortage of labor and space) and/ or productivity losses, except in few months where certain global health risks such as 'bird flu' disease was there that had adverse impact on investments on production cycles and consumer expenses on poultry products.

The models constructed for the purpose of price analysis are sound and adequate to make accurate forecasts of prices of major poultry products; thus, equip the economists and policymakers with appropriate tools for decision making on these essential food items in Sri Lanka. Given

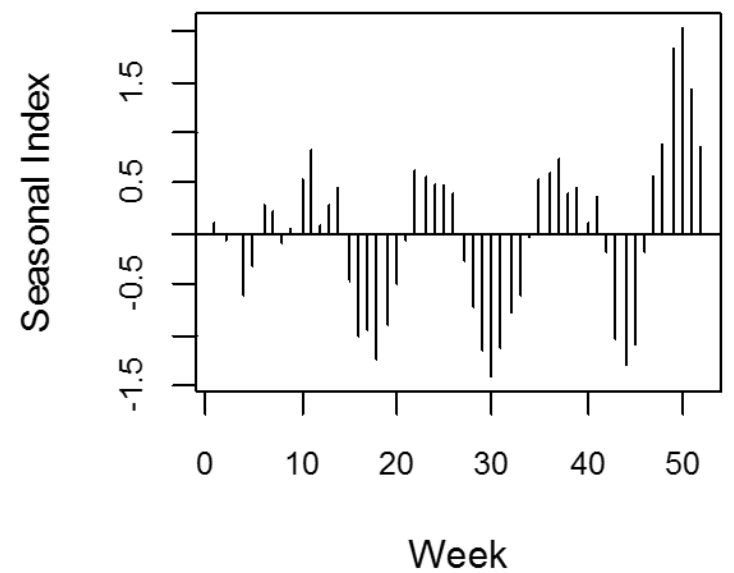

Figure 06: Seasonal index of real prices - White egg

the proven relationships between food prices and food security, the first-hand information generated through the analysis is vital for them to make effective decisions in order to manage unwanted situations created by supply of these products in excess or in deficit by way of various economic instruments such as quota systems and buffer stocks etc. to stabilize prices to maintain food and nutritional security.

Further, it is important to establish codes of conduct, rules and regulations for key players in the industry with the idea of developing a well-functioning food supply chain for the industry, and such must be supported by various fiscal incentives in the form of subsidies, taxes, credits, rebates etc. to promote participation in production, value-addition, and consumption of poultry products. Lessons can be learnt from supply managed systems exist in developed countries like the US, Canada and Australia, where the interests of all parties are safeguarded through such incentives and coregulatory mechanisms. Last but not least, it is of paramount importance to estimate potential production and consumption on different time period, and in turn, how much importation is required in advance to minimize internal and external trade issues, where the coordinated action is warranted and must be guaranteed to make sure both production and marketing systems work systematically under proper guidance and inspection. 


\section{ACKNOWLEDGMENT}

The authors extend their profound gratitude to and Training Institute (HARTI) for providing the Hector Kobbakaduwa Agrarian Research required data for the analysis.

\section{REFERENCES}

Barbu, T. (2013). Variational image denoising approach with diffusion porous media flow, Abstract and Applied Analysis. 2013: Article ID 856876. DOI: http://dx.doi.org/10.1155/2013/856876

Chen, K. Y. and Wang, C. H. (2007). A hybrid SARIMA and support vector machines in forecasting the production values of the machinery industry in Taiwan, Expert Systems with Applications. 32: 254-264. DOI: http://dx.doi.org/10.1016/j.eswa.2005.11.027

Department of Census and Statistics, Sri Lanka. Available from: http://www.statistics.gov.lk/ Indicators/htdocs/index.php? usecase $=$ indicator\&action=Detail\&indId $=001 . \quad$ (Accessed 02 May 2014). DOI: http://dx.doi.org/10.1163/2213-2996_flg_com_174160

Department of Census and Statistics, Sri Lanka. (2012). Livestock population and productionnational level. Available from: http://www.statistics.gov.lk/agriculture/Livestock/ LivestockStatistics.html. (Accessed 25 March 2014). DOI: http://dx.doi.org/10.1163/22132996_flg_com_174160

De Silva, Y. Y. K., Rajapakshe, P. S. K. and Amaralal, K. H, M. L. (2006). Price efficiency in tuna fish marketing in Sri Lanka - An application of cointegration approach, Sri Lanka Journal of Aquatic Sciences. 11: 21-26. DOI: http://dx.doi.org/10.4038/sljas.v11i0.2220

Gerolimetto, M. (2010). ARIMA and SARIMA models. Available from: www.dst.unive. it/ marherita/TSLecturenotes6.pdf. (Accessed 02 June 2014). DOI: http://dx.doi. org/10.1007/978-3-658-06837-0_6

Jayasinghe-Mudalige, U. K. (2006). An economic analysis on spatial integration of regional rice markets in Sri Lanka, Sri Lankan Journal of Agricultural Economics. 8(1): 51-65. DOI: http://dx.doi.org/10.4038/sjae.v8i0.1829

Kwiatkowski, D., Phillips, P. C., Schmidt, P. and Shin, Y. (1992). Testing the null hypothesis of stationarity against the alternative of a unit root: How sure are we that economic time series have a unit root?, Journal of Econometrics. 54(1-3): 159-178. DOI: http://dx.doi. org/10.1016/0304-4076(92)90104-y

Ministry of Social Services, Welfare and Livestock Development (2012). The livestock sector in Sri Lanka. Available from: http://www.livestock.gov.lk/site/en/profile-of-the-livestocksector. (Accessed 09 June 2014). DOI: http://dx.doi.org/10.1504/ajesd.2012.045755

Myers, R. (2006). Costs of food price instability in low-income countries. Food Policy. 31: 288301. DOI: http://dx.doi.org/10.1016/j.foodpol.2006.03.005 
Perera, K. B. P., Herath, H. M. L. K., Jayasinghe-Mudalige, U. K., Edirisinghe, J. C., Udugama, J. M. M. and Wijesuriya, W. (2016), Price analysis of selected marine fish available in Colombo fish markets, Sri Lanka Journal of Economic Research, 4(1): 19 - 33. DOI: http://dx.doi. org/10.4038/jepsl.v4i1.7855

Sahr, R. (2013). Inflation conversion factors for years 1774 to estimated 2024 in dollars of recent years. Available from: http://oregonstate. edu/cla/olisci/sahr/sahr. (Accessed 23 May 2014). DOI: http://dx.doi.org/10.5771/9783845203263

Said, S. E. and Dickey, D. A. (1984). Testing for unit roots in autoregressive-moving average models of unknown order, Biometrika. 71: 599-607. DOI: http://dx.doi.org/10.1093/ biomet/71.3.599

Sandika, A. L. (2009). An Analysis of price behavior of rice in Sri Lanka after liberalization of economy, Tropical Agricultural Research and Extension. 12(2): 81-84. DOI: http://dx.doi. org/10.4038/tare.v12i2.2795

Shumway, R. H. and Stoffer, D. S. (2006). Time series analysis and its applications: With R examples. Springer, New York, USA. DOI: http://dx.doi.org/10.1007/978-1-4419-7865-3

Timmer, P. (2013). Price stabilization, self-sufficiency and food security: some lessons from the Indonesian experience. In: Galtier, F. (Ed.), Managing Food Price Instability in Developing Countries. A Critical Analysis of Strategies and Instruments, AFD, Paris. DOI: http://dx.doi. org/10.1016/j.gfs.2013.02.001

Wijewantha, P., Kothalawala, K. A. C. H. A., Wickramasinghe, U. K. M., Rannasinghe, R. K. K. and Kothalawala, K. A. C. H. A. (2010). Livestock statistical bulletin, Department of Animal Production and Health. Available from: http://www.daph.gov.lk/ web/mages/df/stb201031. pdf (Accessed 23 May 2014). DOI: http://dx.doi.org/10.1080/17441731003603504

Zhang, G. P. (2003). Time series forecasting using a hybrid ARIMA and neural network model, Neurocomputing. 50: 159-175. DOI: http://dx.doi.org/10.1016/s0925-2312(01)00702-0 